\title{
Endothelial dysfunction in patients with Buerger disease
}

This article was published in the following Dove Press journal:

Vascular Health and Risk Management

23 August 2017

Number of times this article has been viewed

\section{Kimihiro Igari \\ Toshifumi Kudo \\ Takahiro Toyofuku \\ Yoshinori Inoue}

Division of Vascular and Endovascular Surgery, Department of Surgery,

Tokyo Medical and Dental University,

Tokyo, Japan
Correspondence: Kimihiro lgari

Division of Vascular and Endovascular

Surgery, Department of Surgery

Tokyo Medical and Dental University,

I-5-45, Yushima, Bunkyo-ku, Tokyo

II 3-8519, Japan

Tel +8I 8358035255

Fax $+8 I 338174126$

Email igari.srgl@tmd.ac.jp
Abstract: We evaluated the endothelial function of patients with Buerger disease using peripheral arterial tonometry test, and examined the factors that are significantly correlated with the endothelial dysfunction in these patients. We performed the peripheral arterial tonometry test in 22 patients with Buerger disease. We recorded the patients' characteristics, including ankle brachial pressure index and reactive hyperemia index, which reflect the endothelial dysfunction. We divided the patients with Buerger disease into the conservative treatment and lumbar sympathectomy group. While the reactive hyperemia index was not significantly different between these two groups, the ankle brachial pressure index was significantly different ( 1.12 versus $0.83, P=0.003$ ). Furthermore, the reactive hyperemia index was significantly correlated with the ankle brachial pressure index value in the patients in the lumbar sympathectomy group ( $\rho=0.848, P=0.005$ ). Given that patients with Buerger disease show impairment of the sympathetic nervous system, we should consider the after-effects of such an impaired system on the condition of these patients. The patients treated with lumbar sympathectomy might be more appropriate to evaluate their endothelial function by a peripheral arterial tonometry test.

Keywords: peripheral arterial disease, Buerger disease, peripheral arterial tonometry, sympathectomy

\section{Introduction}

Buerger disease (thromboangiitis obliterans) is a rare nonatherosclerotic, inflammatory vascular disease characterized by segmental occlusive vascular disease, ${ }^{1}$ which mainly affects the small- and medium-sized arteries and veins. The affected vessels are occluded by the formation of a highly cellular thrombus. ${ }^{2}$ Although substantial evidence supports the notion that inflammatory reactions, including infectious disease, ${ }^{3}$ play key roles in its occurrence, the precise mechanism underlying the development of Buerger disease remains controversial.

Recently, it has been reported that inflammatory reactions exacerbate the severity of Buerger disease. This is supported by the observed increase in the levels of inflammatory cytokines. ${ }^{4}$ These inflammatory cytokines might affect the endothelial function, thereby promoting the development of Buerger disease. Endothelial dysfunction might be recognized and measured before the clinical or symptomatic manifestations of arterial disease..$^{5}$

Some studies have reported an association between Buerger disease and endothelial dysfunction. ${ }^{6,7}$ These reports evaluated the endothelial function by measuring the 
flow-mediated vasodilatation (FMD). This measurement is commonly used to evaluate the endothelial function, which is presented as an index of the endothelium-dependent vasodilating function. ${ }^{8}$ Other measurement methods such as peripheral arterial tonometry (PAT) have also been proposed. PAT investigates the digital pulse amplitude and evaluates the endothelial function on the basis of the changes in the pulsatile volume. ${ }^{9}$ Thus, PAT might reflect the endothelial function more accurately than the FMD does, especially the microvascular endothelial function. ${ }^{10}$ Given that Buerger disease affects smaller-sized arteries to a greater extent than other atherosclerotic peripheral arterial diseases, PAT may be more appropriate than the measurement of FMD for evaluating the endothelial function of Buerger disease patients. However, there are no reports on the use of PAT in the evaluation of the endothelial function in Buerger disease patients.

Thus, in the present study, we used PAT to evaluate the endothelial function and investigated the factors that are correlated with endothelial dysfunction in Buerger disease patients.

\section{Methods}

\section{Patient selection}

This study was a retrospective one. For this, we collected 22 patients with Buerger disease, who were treated at the Tokyo Medical and Dental University Hospital, from June 2014 to June 2015. All of the patients had been previously diagnosed according to Shionoya's clinical criteria, ${ }^{11}$ which included: 1) a history of smoking, 2) an onset before 50 years of age, 3) the presence of infrapopliteal arterial occlusions, 4) either upper limb involvement or phlebitis migrans, and 5) the absence of atherosclerotic risk factors other than smoking. To confirm the diagnosis as Buerger disease more precisely, we performed angiography to evaluate the patients' arterial lesions. All of the patients showed the typical angiography findings, such as a corkscrew appearance, abrupt interruption, and the absence of calcification.

We included only those patients who were in the remission phase of Buerger disease, as the endothelial function evaluated using the FMD test is normal during the acute exacerbation phase ${ }^{6}$ and who had been in remission for at least 6 months. The patients with recent (within 6 months) interventions for coronary artery disease (CAD) and/or peripheral arterial disease were excluded from this study. Furthermore, we excluded the patients who had a recent (within the past 3 months) history of CAD, such as myocardial infarction, unstable angina, and decompensated heart failure, or cerebrovascular disease (CVD) - conditions that might affect the PAT measurements. The patients with systemic inflammatory and malignant diseases were also excluded from this study.

We examined and reviewed the patients' medical examinations and records after obtaining approval for the present study from the ethics committee of our university (No. 701). We confirmed that written informed consent was obtained from all of the patients before enrolling them in the study. Furthermore, we confirmed that all of the methods were performed in accordance with the relevant ethical guidelines and regulations. In all cases, we examined the medical history, hemodynamic evaluations, and endothelial function test results. With regard to the patients' medical history, the following definitions were applied. Hypertension was defined as a history of treatment for hypertension and/or a systolic blood pressure $>130 \mathrm{mmHg}$, and/or a diastolic blood pressure $>80$ $\mathrm{mmHg}$. Dyslipidemia was also diagnosed, based on the blood test, such as a serum low-density lipoprotein cholesterol level $>140 \mathrm{mg} / \mathrm{dL}$, a high-density lipoprotein cholesterol level $<40$ $\mathrm{mg} / \mathrm{dL}$, and a triglyceride level $>150 \mathrm{mg} / \mathrm{dL}$. The patients with a history of treatment for dyslipidemia were defined as the patients with dyslipidemia. CAD was diagnosed on the basis of the history of ischemic coronary disease including angina pectoris, myocardial infarction, and/or on a history of the patient having undergone coronary artery revascularization. We diagnosed the presence of CVD on the basis of a history of transient ischemic attack, stroke, cerebral hemorrhage, or carotid artery revascularization. Chronic kidney disease (CKD) was defined on the basis of a blood test that evaluated an estimated glomerular filtration rate $<60 \mathrm{~mL} / \mathrm{min} / 1.73 \mathrm{~m}^{2}$. Diabetes mellitus (DM) was defined by a fasting blood glucose level $>126 \mathrm{mg} / \mathrm{dL}$, by a hemoglobin A1c concentration $>6.5 \%$, or by the use of antidiabetic drugs.

The ankle brachial pressure index (ABI) was examined for the purpose of evaluating the hemodynamic severity of Buerger disease. We examined the ABI using a VasoGuard P84 ${ }^{\mathrm{TM}}$ system (SciMed Ltd., Bristol, UK). Furthermore, we evaluated the patients' clinical ischemic conditions according to the Rutherford classification. ${ }^{12}$

\section{Endothelial function test}

We performed PAT as described below. The amplitude of the pulse wave was assessed twice (before and during reactive hyperemia). To evaluate the reactive hyperemia, we had to occlude the blood flow of the brachial artery with an inflatable cuff. The reactive hyperemia index (RHI) between the flow in the control upper arm and the upper arm with reactive 
hyperemia was calculated with the help of the EndoPAT 2000 device (Itamar Medical Ltd., Caesarea, Israel) to express the endothelial function. ${ }^{13}$

To evaluate the RHI precisely, we asked the patients to refrain from smoking, drinking caffeine-containing beverages, and eating food. Furthermore, the patients had to stop taking all drugs from 12 hours before PAT. In a supine position, the patients were examined for PAT in the room with a quiet and constant temperature of $20^{\circ} \mathrm{C}$. The PAT started with the placing of a configured finger probe on the index finger of each hand of the patients and a pressure cuff on one upper arm. We continuously detected the PAT signals from both fingers for $10 \mathrm{~min}$. Then, we inflated the blood pressure cuff to $200 \mathrm{mmHg}$ for $5 \mathrm{~min}$ and deflated. We could record the changes in the PAT signal for the next $10 \mathrm{~min}$. The pressure changes reflecting the pulse amplitude in both the preinflation and postdeflation periods were transmitted to a computer, and the RHI was automatically calculated. ${ }^{14} \mathrm{We}$ have already shown the accuracy of our PAT measurement method in a previous report. ${ }^{15}$

\section{Statistical analysis}

The categorical variables are expressed as frequencies and percentages, and the continuous variables are expressed as the median and interquartile range (IQR). The statistical significance of continuous variables and categorical variables was assessed using the Mann-Whitney $U$-test and Fisher's exact test, respectively. The correlations between the RHI and several parameters in Buerger disease patients were assessed using Spearman's correlation coefficient or Fisher $r$ to $z$ transformation. $P$ values of $<0.05$ were considered to indicate statistical significance. The statistical analyses were performed using the StatView software program (version 5; Abacus Concept Inc., Berkley, CA, USA).

\section{Results}

\section{The patients' characteristics}

The characteristics of the 22 male Buerger disease patients who were evaluated in the present study are shown in Table 1. All of the patients were former or current smokers. The median age was 57 years (IQR, 47-63 years), and the median body mass index was $23.9 \mathrm{~kg} / \mathrm{m}^{2}$ (IQR, 21.5-25.5). Seventeen patients $(72.2 \%)$ were taking at least one antiplatelet agent, and two patients $(9.1 \%)$ were taking statins. Two patients $(9.1 \%)$ were using $\mathrm{Ca}$ channel blockers. No patient was treated with $\beta$-blockers or nitroglycerin. The documented comorbidities included hypertension (13.6\%), dyslipidemia (9.1\%), CVD (4.5\%), CKD (4.5\%), and DM
Table I Patients' characteristics

\begin{tabular}{|c|c|}
\hline Variables & $n=22$ \\
\hline Age (years) & $57.0(47.3-66.3)$ \\
\hline BMI $\left(\mathrm{kg} / \mathrm{m}^{2}\right)$ & $23.9(21.5-25.5)$ \\
\hline \multicolumn{2}{|l|}{ Comorbidities } \\
\hline Hypertension & $3(13.6 \%)$ \\
\hline Dyslipidemia & $2(9.1 \%)$ \\
\hline CAD & $0(0 \%)$ \\
\hline CVD & I (4.5\%) \\
\hline CKD & I (4.5\%) \\
\hline DM & I (4.5\%) \\
\hline \multicolumn{2}{|l|}{ Medications } \\
\hline Antiplatelet & 17 (77.2\%) \\
\hline Statin & $2(9.1 \%)$ \\
\hline Nitroglycerin & $0(0 \%)$ \\
\hline Ca-blocker & $2(9.1 \%)$ \\
\hline$\beta$-blocker & $0(0 \%)$ \\
\hline \multicolumn{2}{|l|}{ Treatment } \\
\hline Conservative treatment & $10(45.5 \%)$ \\
\hline Lumbar sympathectomy & $12(54.5 \%)$ \\
\hline \multicolumn{2}{|c|}{ Hemodynamical parameters } \\
\hline$A B I$ & $1.03(0.75-1.12)$ \\
\hline $\mathrm{RHI}$ & I.7I (1.25-2.27) \\
\hline \multicolumn{2}{|c|}{ Rutherford classification } \\
\hline Category 2: 3: 4: 5: 6 & 9:6: 4: 2: I \\
\hline \multicolumn{2}{|l|}{ Laboratory findings } \\
\hline WBC $(/ \mu \mathrm{L})$ & $5300(4725-7325)$ \\
\hline Hemoglobin $(\mathrm{g} / \mathrm{dL})$ & $14.6(13.9-15.2)$ \\
\hline Platelet $\left(\times 10^{4} / \mu \mathrm{L}\right)$ & $24.2(20.5-30.6)$ \\
\hline PT (\%) & $99.0(93.0-105.5)$ \\
\hline APTT (s) & $29.1(27.7-30.4)$ \\
\hline Fibrinogen (mg/dL) & $296(268-323)$ \\
\hline Creatinine $(\mathrm{mg} / \mathrm{dL})$ & $0.81(0.75-0.91)$ \\
\hline T-Chol (mg/dL) & $207(\mid 83-217)$ \\
\hline Triglycerides (mg/dL) & $130(78-145)$ \\
\hline Hemoglobin Alc (\%) & $5.70(5.60-6.30)$ \\
\hline $\mathrm{CRP}(\mathrm{mg} / \mathrm{dL})$ & $0.09(0.03-0.16)$ \\
\hline
\end{tabular}

Notes: Data presented as mean (IQR) unless otherwise noted.

Abbreviations: $A B I$, ankle brachial pressure index; APTT, activated partial thromboplastin time; BMI, body mass index; $C A D$, coronary artery disease; CKD, chronic kidney disease; CRP, C-reactive protein; CVD, cerebrovascular disease; $\mathrm{DM}$, diabetes mellitus; $\mathrm{PT}$, prothrombin time; $\mathrm{RHI}$, reactive hyperemia index; T-Chol, total cholesterol; WBC, white blood cell; IQR, interquartile range.

$(4.5 \%)$. Ten of the twenty-two patients $(45.5 \%)$ were treated by conservative, nonsurgical treatments; the remaining 12 (54.5\%) underwent lumbar sympathectomy. The laboratory test findings are also shown in Table 1 . In the hemodynamical points of view, the median ABI was 1.03 (IQR, 0.75-1.12), and the median RHI as measured by PAT was 1.71 (IQR, 1.25-2.27).

\section{The correlations between the $\mathrm{RHI}$ and various parameters}

The correlations between the RHI and various parameters in our patient population are shown in Table 2. None of the evaluated parameters showed any significant correlations with RHI. 
Table 2 Correlations between endothelial dysfunction and variable parameters

\begin{tabular}{|c|c|c|}
\hline Variables & $\begin{array}{l}\text { Correlation } \\
\text { coefficient }\end{array}$ & $P$-value \\
\hline Age & 0.254 & 0.244 \\
\hline BMI & -0.130 & 0.551 \\
\hline \multicolumn{3}{|l|}{ Comorbidities } \\
\hline Hypertension & -0.089 & 0.697 \\
\hline Dyslipidemia & -0.101 & 0.660 \\
\hline CAD & - & - \\
\hline CVD & 0.193 & 0.394 \\
\hline CKD & -0.031 & 0.891 \\
\hline DM & -0.031 & 0.891 \\
\hline \multicolumn{3}{|l|}{ Medications } \\
\hline Antiplatelet & 0.144 & 0.528 \\
\hline Statin & -0.101 & 0.660 \\
\hline Nitroglycerin & - & - \\
\hline Ca-blocker & 0.010 & 0.967 \\
\hline$\beta$-blocker & - & - \\
\hline \multicolumn{3}{|c|}{ Hemodynamical parameters } \\
\hline$A B I$ & 0.228 & 0.296 \\
\hline \multicolumn{3}{|l|}{ Laboratory findings } \\
\hline WBC & -0.380 & 0.082 \\
\hline Hemoglobin & -0.272 & 0.213 \\
\hline Platelet & -0.118 & 0.589 \\
\hline PT & 0.096 & 0.666 \\
\hline APTT & -0.167 & 0.466 \\
\hline Fibrinogen & -0.029 & 0.900 \\
\hline Creatinine (mg/dL) & 0.061 & 0.779 \\
\hline T-Chol (mg/dL) & 0.293 & 0.190 \\
\hline Triglycerides (mg/dL) & -0.184 & 0.410 \\
\hline Hemoglobin Alc (\%) & -0.104 & 0.718 \\
\hline CRP (mg/dL) & -0.209 & 0.338 \\
\hline
\end{tabular}

Abbreviations: $A B I$, ankle brachial pressure index; APTT, activated partial thromboplastin time; $B M I$, body mass index; $C A D$, coronary artery disease; $C K D$, chronic kidney disease; CRP, C-reactive protein; CVD, cerebrovascular disease; DM, diabetes mellitus; PT, prothrombin time; T-Chol, total cholesterol; RHI, reactive hyperemia index; WBC, white blood cell.

\section{Comparisons between patients treated by lumbar sympathectomy and conservative treatment}

We divided the patients on the basis of the type of treatment they had received into a lumbar sympathectomy group and a conservative treatment group and compared the parameters between the groups (Table 3). With the exception of the ABI, none of the evaluated parameters differed significantly between the groups. Furthermore, we could not detect the significance in RHI between a lumbar sympathectomy group and a conservative treatment group (Figure 1). The ABI in the lumbar sympathectomy group was significantly lower than that in the conservative treatment group ( 0.83 versus $1.12, P=0.003)$. On the basis of the results of the statistical analysis, we determined that the effect size was 1.56 ; thus, the statistical power was 0.96 , and the probability of a type II error was 0.04 .

Furthermore, we evaluated the correlation between the RHI and ABI in each treatment group (Table 4). Although the ABI was not significantly correlated with the RHI in the conservative treatment group ( $\rho=-0.121, P=0.716$ ), Figure 2 showed that the ABI was significantly correlated with the RHI in the lumbar sympathectomy group ( $\rho=0.848, P=0.005$ ). With regard to type II errors, we determined that the statistical power was 0.97 ; thus, a type II error would not show in the results of this statistical analysis.

\section{Discussion}

In this study, we evaluated the endothelial function of patients with Buerger disease by PAT. The precise mechanism underlying the endothelial dysfunction in these patients remains unclear. However, while several authors ${ }^{16,17}$ have reported that Buerger disease is associated with endothelial dysfunction, the function was largely evaluated on the basis of the FMD. To our knowledge, this is the first study to evaluate the endothelial dysfunction of Buerger disease patients.

In the present study, we divided the patients into a conservative treatment group and a lumbar sympathectomy group on the basis of the treatment they had received. No notable differences in the RHI measured by PAT were observed between these groups (1.82 [conservative treatment group] versus 1.69 [lumbar sympathectomy group]; $P=0.843$ ). However, the ABI in the lumbar sympathectomy group was significantly lower than that in the conservative treatment group. The patients treated by lumbar sympathectomy showed more severe ischemic symptoms than those who received conservative treatment, which might have led to the significantly lower ABI among the patients in the lumbar sympathectomy group. While no significant correlation was observed between the $\mathrm{ABI}$ and $\mathrm{RHI}$ in the conservative treatment group, a significant correlation was observed in the lumbar sympathectomy group.

Several reasons might have led to this difference. First, the sympathetic nervous system is reportedly suppressed in Buerger disease patients, ${ }^{18}$ and the catecholamine levels in Buerger disease patients were lower than those in healthy subjects. ${ }^{19}$ The impairment of the sympathetic nervous system in the conservative treatment group might have interfered with the PAT results, because sympathetic nervous systemmodifying agents such as $\beta$-blockers have been shown to influence the outcomes of the FMD test. ${ }^{20}$ Second, the RHI was significantly correlated with the $\mathrm{ABI}$ in our patients 
Table 3 Comparisons of patients' characteristics

\begin{tabular}{|c|c|c|c|}
\hline Variables & Conservative treatment $(n=10)$ & Lumbar sympathectomy $(n=12)$ & $P$-value \\
\hline Age (years) & $60.0(50.3-66.3)$ & $52.0(43.5-62.5)$ & 0.199 \\
\hline BMI $\left(\mathrm{kg} / \mathrm{m}^{2}\right)$ & $24.0(22.8-25.5)$ & $22.5(20.6-24.8)$ & 0.356 \\
\hline \multicolumn{4}{|l|}{ Comorbidities } \\
\hline Hypertension & $3(30 \%)$ & $0(0 \%)$ & 0.078 \\
\hline Dyslipidemia & $2(20 \%)$ & $0(0 \%)$ & 0.195 \\
\hline CAD & $0(0 \%)$ & $0(0 \%)$ & - \\
\hline CVD & $0(0 \%)$ & I (8.3\%) & $>0.999$ \\
\hline CKD & I (10\%) & $0(0 \%)$ & 0.455 \\
\hline DM & $\mathrm{I}(10 \%)$ & $0(0 \%)$ & 0.455 \\
\hline \multicolumn{4}{|l|}{ Medications } \\
\hline Antiplatelet & $7(70 \%)$ & $10(83.3 \%)$ & 0.624 \\
\hline Statin & $2(20 \%)$ & $0(0 \%)$ & 0.195 \\
\hline Nitroglycerin & $0(0 \%)$ & $0(0 \%)$ & - \\
\hline Ca-blocker & $2(20 \%)$ & $0(0 \%)$ & 0.195 \\
\hline$\beta$-blocker & $0(0 \%)$ & $0(0 \%)$ & - \\
\hline \multicolumn{4}{|c|}{ Hemodynamical parameters } \\
\hline$A B I$ & $1.12(1.07-1.19)$ & $0.83(0.72-1.03)$ & 0.003 \\
\hline RHI & $1.82(1.25-2.28)$ & $1.69(1.26-1.91)$ & 0.843 \\
\hline \multicolumn{4}{|l|}{ Laboratory findings } \\
\hline WBC $(/ \mu \mathrm{L})$ & $5150(4700-6900)$ & $6050(4875-8325)$ & 0.277 \\
\hline Hemoglobin (g/dL) & $14.5(13.7-15.4)$ & $\mid 4.8(\mid 4.5-15.0)$ & 0.818 \\
\hline Platelet $\left(\times 10^{4} / \mu \mathrm{L}\right)$ & $24.5(20.2-29.5)$ & $24.2(21.4-32.2)$ & 0.429 \\
\hline PT (\%) & $104.3(99.0-105.5)$ & $93.0(90.3-99.4)$ & 0.067 \\
\hline APTT (sec) & $29.2(28.0-32.3)$ & $29.0(27.2-30.3)$ & 0.227 \\
\hline Fibrinogen (mg/dL) & $285(267-290)$ & $314(30 \mathrm{I}-324)$ & 0.257 \\
\hline Creatinine $(\mathrm{mg} / \mathrm{dL})$ & $0.82(0.78-0.93)$ & $0.78(0.75-0.90)$ & 0.448 \\
\hline T-Chol (mg/dL) & $183(177-217)$ & $207(199-221)$ & 0.155 \\
\hline Triglycerides (mg/dL) & $130(119-144)$ & $85(6 \mid-147)$ & 0.155 \\
\hline Hemoglobin Alc (\%) & $5.85(5.70-6.23)$ & $5.6(5.5-6.3)$ & 0.568 \\
\hline CRP $(\mathrm{mg} / \mathrm{dL})$ & $0.07(0.03-0.16)$ & $0.10(0.04-0.20)$ & 0.621 \\
\hline
\end{tabular}

Notes: Data presented as mean (IQR) unless otherwise noted.

Abbreviations: $A B I$, ankle brachial pressure index; APTT, activated partial thromboplastin time; BMI, body mass index; CAD, coronary artery disease; CKD, chronic kidney disease; CRP, C-reactive protein; CVD, cerebrovascular disease; DM, diabetes mellitus; PT, prothrombin time; RHI, reactive hyperemia index; T-Chol, total cholesterol; WBC, white blood cell; IQR, interquartile range.

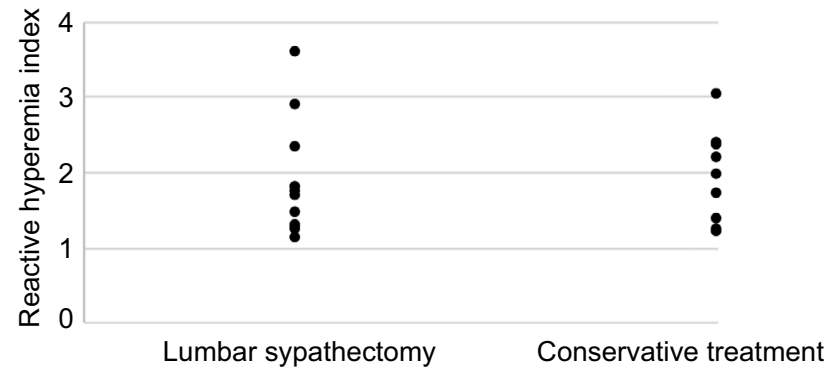

Figure I Reactive hyperemia index in the lumbar sympathectomy group and in the conservative treatment group.

Table 4 The correlations between ankle brachial pressure index and reactive hyperemia index

\begin{tabular}{lll}
\hline Group & $\boldsymbol{\rho}$ & $\boldsymbol{P}$-value \\
\hline Conservative treatment & -0.121 & 0.716 \\
Lumbar sympathectomy & 0.848 & 0.005 \\
\hline
\end{tabular}

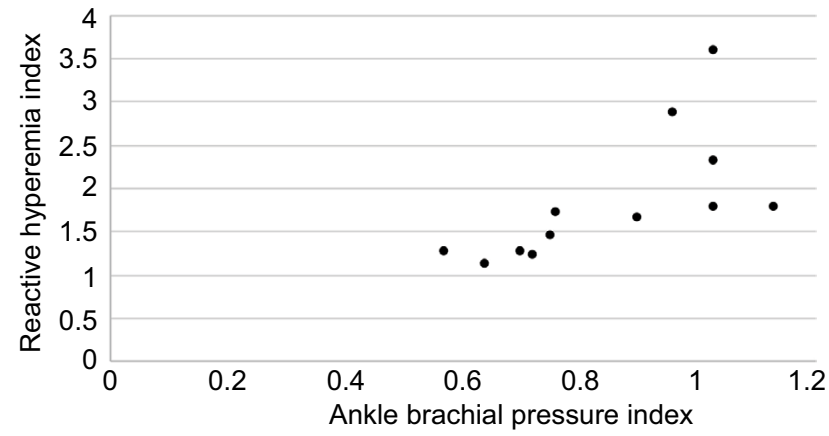

Figure 2 The correlation between ankle brachial pressure index and reactive hyperemia index in the lumbar sympathectomy group.

with lumbar sympathectomy. Lumbar sympathectomy might increase the serum level of catecholamines, ${ }^{19}$ which might subsequently improve the impaired sympathetic nervous system of Buerger disease patients. Some authors have reported the association between the endothelial dysfunction measured 
using the FMD test and the ABI. ${ }^{21,22}$ Thus, the endothelial dysfunction measured using PAT might also be correlated with the ABI, which was obvious in our results.

However, the present study has several limitations. First, direct comparisons between Buerger disease patients and healthy subjects might more concretely confirm the clinical significance of PAT. Furthermore, the patients with conservative treatment were treated with several kinds of medications, which might affect our results. Second, the study population was small, which might have affected the statistical significance. Although the statistical power analysis yielded some significant results, there might have been type I or type II errors. To our knowledge, no previous study has evaluated the endothelial function using PAT. Thus, future studies should be conducted in a larger population and the findings in healthy subjects and Buerger disease patients should be compared.

In conclusion, we evaluated the endothelial function in Buerger disease patients using PAT. While we did not observe any correlation between the endothelial dysfunction and the ABI in the patients who underwent conservative treatment due to the impaired sympathetic nervous system, we detected a significant correlation between the RHI and ABI in the patients who underwent lumbar sympathectomy. This result might support the hypothesis that lumbar sympathectomy improves the impaired sympathetic nervous system.

\section{Disclosure}

This research did not receive any specific grant from funding agencies in the public, commercial, or not-for-profit sectors. The authors report no conflicts of interest in this work.

\section{References}

1. Olin JW. Thromboangiitis obliterans (Buerger's disease). NEngl JMed. 2000;343:864-869.

2. Igari $\mathrm{K}$, Inoue $\mathrm{Y}$, Iwai T. The epidemiological and clinical findings of patients with Buerger disease. Ann Vasc Surg. 2016;30:263-269.

3. Iwai T, Inoue $Y$, Umeda M, et al. Oral bacteria in the occluded arteries of patients with Buerger disease. J Vasc Surg. 2005;42(1):107-115.

4. Slavov ES, Stanilova SA, Petkov DP, Dobreva ZG. Cytokine production in thromboangiitis obliterans patients: new evidence for an immune-mediated inflammatory disorder. Clin Exp Rheumatol. $2005 ; 23(2): 219-226$.
5. Celermajer DS, Sorensen KE, Bull C, Robinson J, Deanfield JE. Endothelium-dependent dilation in the systemic arteries of asymptomatic subjects relates to coronary risk factors and their interaction. $J \mathrm{Am}$ Coll Cardiol. 1994;24(6):1468-1474.

6. Azizi M, Boutouyrie P, Bura-Riviere A, Peyrard S, Laurent S, Fiessinger JN. Thromboangiitis obliterans and endothelial function. Eur J Clin Invest. 2010;40(6):518-526.

7. Fujii Y, Fujimura N, Mikami S, et al. Flow-mediated vasodilation is augmented in a corkscrew collateral artery compared with that in a native artery in patients with thromboangiitis obliterans (Buerger disease). J Vasc Surg. 2011;54(6):1689-1697.

8. Donald AE, Halcox JP, Charakida M, et al. Methodological approaches to optimize reproducibility and power in clinical studies of flowmediated dilation. J Am Coll Cardiol. 2008;51(20):1959-1964.

9. Bonetti PO, Pumper GM, Higano ST, Holmes DR Jr, Kuvin JT, Lerman A. Non-invasive identification of patients with early coronary atherosclerosis by assessment of digital reactive hyperemia. $J \mathrm{Am}$ Coll Cardiol. 2004;44:2137-2141.

10. Poredos P, Jezovnik MK. Testing endothelial function and its clinical relevance. J Atheroscler Thromb. 2013;20(1):1-8.

11. Shionoya S. Diagnostic criteria of Buerger's disease. Int J Cardiol. 1988;66(Suppl 1):S243-S245.

12. Rutherford RB, Baker JD, Ernst C, et al. Recommended standards for reports dealing with lower extremity ischemia: revised version. J Vasc Surg. 1997;26(3):517-538.

13. Kuvin JT, Patel AR, Sliney KA, et al. Assessment of peripheral vascular endothelial function with finger arterial pulse wave amplitude. $\mathrm{Am}$ Heart J. 2003;146(1):168-174.

14. Bonetti PO, Barsness GW, Keelan PC, et al. Enhanced external counterpulsation improves endothelial function in patients with symptomatic coronary artery disease. J Am Coll Cardiol. 2003;41(10):1761-1768.

15. Igari K, Kudo T, Toyofuku T, Inoue Y. The relationship between endothelial dysfunction and endothelial cell markers in peripheral arterial disease. PLoS One. 2016;11(11):e0166840.

16. Joras M, Poredos P, Fras Z. Endothelial dysfunction in Buerger's disease and its relation to markers of inflammation. Eur J Clin Invest. 2006;36(6):376-382.

17. Makita S, Nakamura M, Murakami H, Komoda K, Kawazoe K, Hiramori $\mathrm{K}$. Impaired endothelium-dependent vasorelaxation in peripheral vasculature of patients with thromboangiitis obliterans (Buerger's disease). Circulation. 1996;94(Supp1 9):II211-II215.

18. Iwase S, Okamoto T, Mano T, et al. Skin sympathetic outflow in Buerger's disease. Auton Neurosci. 2001;87:286-292.

19. Roncon-Albuquerque R, Serrao P, Vale-Pereira R, Costa-Lima J, Roncon-Albuquerque R Jr. Plasma catecholamines in Buerger's disease: effects of cigarette smoking and surgical sympathectomy. Eur J Vasc Endovasc Surg. 2002;24(4):338-343.

20. Watanabe S, Amiya E, Watanabe M, et al. Simultaneous heart rate variability monitoring enhances the predictive value of flow-mediated dilation in ischemic heart disease. Circ J. 2013;77(4):1018-1025.

21. Brevetti G, Martone VD, de Cristoforo T, et al. High levels of adhesion molecules are associated with impaired endothelium-dependent vasodilatation in patients with peripheral arterial disease. Thromb Haemost. 2001;85(1):63-66.

22. Silvestro A, Scopacasa F, Oliva G, de Cristofaro T, Iuliano L, Brevetti G. Vitamin $C$ prevents endothelial dysfunction induced by acute exercise in patients with intermittent claudication. Atherosclerosis. 2002;165(2):277-283. 


\section{Publish your work in this journal}

Vascular Health and Risk Management is an international, peerreviewed journal of therapeutics and risk management, focusing on concise rapid reporting of clinical studies on the processes involved in the maintenance of vascular health; the monitoring, prevention and treatment of vascular disease and its sequelae; and the involvement of metabolic disorders, particularly diabetes. This journal is indexed on PubMed Central and MedLine. The manuscript management system is completely online and includes a very quick and fair peer-review system, which is all easy to use. Visit http://www.dovepress.com/ testimonials.php to read real quotes from published authors.

Submit your manuscript here: https://www.dovepress.com/vascular-health-and-risk-management-journal 